\title{
Study for Reduction of Pollution Level in Diesel Engines, Petrol Engines and Generator Sets by Bio-Signal Ring
}

\author{
Singh SK, Surbhi Jain*, Tejasvini Ahuja, Yukti Sharma and Nidhi Pathak \\ Department of Environmental Engineering, India
}

*Corresponding author: Surbhi Jain, India

Submission: 㘹June 01, 2018; Published: 觜 July 27, 2018

\begin{abstract}
Air pollution has become a growing problem in megacities and large urban areas throughout the globe, and transportation is recognized as the major source of air pollution in many cities, especially in developing countries. Contribution of automobiles is reported in the range of 40 to $80 \%$ of the total air pollution. The challenge facing megacities is how to reduce the adverse environmental impacts and other negative effects of transportation without giving up the benefits of mobility. This research paper includes the testing of bio-signal ring developed by Wellan International Limited for reduction of pollution levels in petrol and diesel vehicles and generator sets. The ring when attached to the inlet of the fuel pipe acts on the fuel through bio-signals. The bio-signals help in atomization of the fuel and reduce the pollutants by further enhancing the combustion process, and thus reducing the un-burnt pollutant particles from the exhaust. The ring was tested on diesel engines, petrol engines and generator sets. For diesel engine and generator set, reduction in smoke was measured, while in the petrol engine parameters such as $\mathrm{CO}, \mathrm{CO}_{2}, \mathrm{SO}_{x}$ and $\mathrm{NO}_{x}$ were measured before and after attaching the ring. The percentage reduction of the pollutants obtained from the ring for the diesel engine is about $16.4 \%$, and in petrol engine, significant reduction in the pollutants is observed. The average reduction in the opacity of the diesel generator set exhaust was $54.7 \%$. Therefore, it is evident that the device can effectively control the issue of rising air pollution levels in residential, commercial as well as industrial zones.
\end{abstract}

Keywords: Bio-signal; Atomization; Diesel engine; Petrol engine; Generator set; Fuel combustion

\section{Introduction}

A bio-signal is any signal in living beings that can be continually measured and monitored. The term bio-signal is often used to refer to bioelectrical signals, but it may refer to both electrical and nonelectrical signals. The usual understanding is to refer only to timevarying signals, although spatial parameter variations (e.g. the nucleotide sequence determining the genetic code) are sometimes subsumed as well. There are various types of bio-signals. Some of them are stated. Electrical bio-signals, or bioelectrical time signals, usually refer to the change in electric current produced by the sum of an electrical potential difference across a specialized tissue, organ or cell system like the nervous system. Thus, among the bestknown bioelectrical signals are: Electroencephalogram (EEG) is an electrophysiological monitoring method to record electrical activity of the brain. EEG measures voltage fluctuations resulting from ionic current within the neurons of the brain. Electrocardiography (ECG) is the process of recording the electrical activity of the heart over a period of time using electrodes placed on the skin. Electromyography (EMG) is an electro diagnostic medicine technique for evaluating and recording the electrical activity produced by skeletal muscles. Mechanomyogram (MMG) is the mechanical signal observable from the surface of a muscle when the muscle is contracted. At the onset of muscle contraction, gross changes in the muscle shape cause a large peak in the MMG [1-5].

Electro-Oculo-Graphy (EOG/E.O.G.) is a technique for measuring the cornea-retinal standing potential that exists between the front and the back of the human eye. The resulting signal is called the electrooculo gram .Electro dermal activity (EDA) is the property of the human body that causes continuous variation in the electrical characteristics of the skin. Magneto-Encephalo-Graphy (MEG) is a functional Neuro imaging technique for mapping brain activity by recording magnetic fields produced by electrical currents occurring naturally in the brain, using very sensitive magnetometers. Biosignals may also refer to any non-electrical signal that is capable of being monitored from biological beings, such as Mechanical signals (e.g. the Mechanomyogram or MMG), Acoustic signals (e.g. phonetic and non-phonetic utterances, breathing), Chemical signals (e.g. pH, oxygenation) and Optical signals (e.g. movements).

Bio-signals have various applications like water purification, non-invasive diagnosis, potential for direct interfaces and health 
monitoring, bio-signal monitoring system for mobile telemedicine, ways of interaction using bio-signals etc. For water purification, bio-signals can be used by storing in rings called power rings. Power rings work through bio-signals, which have been stored in the rings' interior. These signals penetrate all pipes and tubes to influence the water which is passing through. As a result, the vibrations or oscillations created in the water are changed in such a way that lime [6], rust, scale or bio-fouling matter no longer accumulate within a piped system and are washed out in minute particles. They can also be used for non-invasive diagnosis. In recent years, a particular challenge has arisen in non-invasive medical diagnostic procedures. Because bio-signals recorded on the body surface reflect the internal behaviour and status of the organism or its parts, they are ideally suited to provide essential information of these organs to the clinician without any invasive measures.

Potential for direct interfaces and health monitoring: Biosignals are harnessed to enable enhanced computer interfaces. In particular, bio-signals can serve for passive health monitoring for the elderly who want to remain at home but need some level of support as they age. Such devices can directly manipulate computer interfaces to give people with limited peripheral mobility some control over their environment. Bio-signal monitoring system for mobile telemedicine is yet another application. In this, a prototype integrated mobile telemedicine system has been designed that is compatible with existing public mobile telecommunication network. The mobile telemedicine system consists of two parts. One is a physiological signal measuring part, and the other is a PC system for the signal processing and telecommunication. The system uses NetMeeting to transmit video, audio and patient biosignals from a moving ambulance to a hospital and delivers to the personal computer of the doctor. This PC based mobile telemedicine system is flexible enough to accommodate newer components in wireless communication and portable sensing technologies. There can be ways of interactions using bio-signals. A prototype earphone was developed with three kinds of bio-signals-pulse wave, electromyogram (EMG) and acceleration sensors. Using this system three new applications were invented, namely, automatic music selection, tactile and visual communication and automatic metadata annotation. In numerous methods to control pollution have been employed since the awareness of pollution rise has been spread [7-10].

For example, a muffler is installed in the engine to control the noise and vibrations due to knocking. Earlier, a Positive Crankcase Ventilation (PCV) system was used in the automobiles. In this system, the exhaust gasses were sent back into the crankcase so that complete combustion of the un-burnt particles could be carried out. But, this did not prove to be an effective method since the efficiency was not as desired. Also, the exhaust gasses caused harm to the crankcase. These days, a new technology has been developed. IC engines employ catalytic convertor at their exhaust valves to reduce the smoke emissions. Inside the catalytic convertor, the smoke emissions are adsorbed on the catalyst which makes them unstable, thereby atomizing them. The atomized exhaust gets converted into non-toxic molecules which enter the atmosphere. It proves to be very efficient in reducing the smoke emissions from the engine exhaust valves. In this paper study for reduction of pollution levels in emissions from petrol and diesel vehicles has been done.

\section{Pollution Control by Bio-Signals}

Each elemental molecule has its own specific natural atomic/ molecular oscillation. In simple terms, oscillations are best described as vibrations or waves that are given off by that element. Molecules are formed when atoms of different elements fuse together because of natural affinity. This attraction is caused by the oscillations emitted by the atoms. In other words, elements recognize each other by their unique oscillations. If the oscillations of various atoms are neutralized their attraction ceases. This is the basis of pollution control by bio-signals. The molecules of the fuel are targeted in order to reduce pollution cause by combustion of these particles [11-14].

When the fuel particles are acted upon by the bio-signals, it leads to the atomization of the fuel. So, when the fuel is burned in engine, it leads to the better and uniform combustion [15]. High frequency bio-signals are modulated and stored into an appropriate device which is basically high-quality information storage materials (base material crystals) which are capable of storing such vibrations for indefinite periods of time and releasing them again. These biosignals penetrate any kind of material and they are absorbed by the fuel as interference or resonance vibrations. Whenever extra atoms are forcibly fused to form a molecule by the use of a catalyst, the resultant molecule is unstable and will break apart. Bio-signal emissions cause such a situation, resulting in a breakdown within molecules. The dispersed atoms are then targeted by the ring to keep from restructuring [16]. The high frequency oscillations that are generated by the energy field interact with the molecular structure of the fuel, removing harmful elements from your fuel and oil. This causes the fuel to become cleaner and finer, leading to better combustion and lesser number of un-burnt particles or pollutants and hence reducing pollution.

\section{Functioning of the power ring}

Power ring consists of high-quality information storage materials (base material crystals) which are capable of storing such vibrations for indefinite periods of time and releasing them again. These vibrations penetrate any kind of material and they are absorbed by the water as interference or resonance vibrations (hydrogen bridges or water molecules). Within fractions of a second, this information passes through the pipe into the water and is effective even with high flow rates. Power rings can be deployed for water of any quality. No chemical substances, magnetic fields or electromagnetic radiations are released into the environment. The basis of this technology is the realization of the latest knowledge of modern quantum theory [17].

Frequency patterns from the ultra-fine range (quantum vibrations) are modulated onto POWER RINGS by means of a laser technology. Elements recognize each other by their unique 
oscillations. Thus, a water molecule is formed when oxygen is attracted to combine with 2 atoms of hydrogen. If the oscillations of various atoms are neutralized their attraction ceases. That is the function of Power ring emissions. Whenever extra atoms are forcibly fused to form a molecule by the use of a catalyst, the resultant molecule is unstable and will break apart. Power ring emissions cause such a situation, resulting in a breakdown within molecules. The dispersed atoms are then targeted by the ring to keep from restructuring [18-21]; (Figure 1).

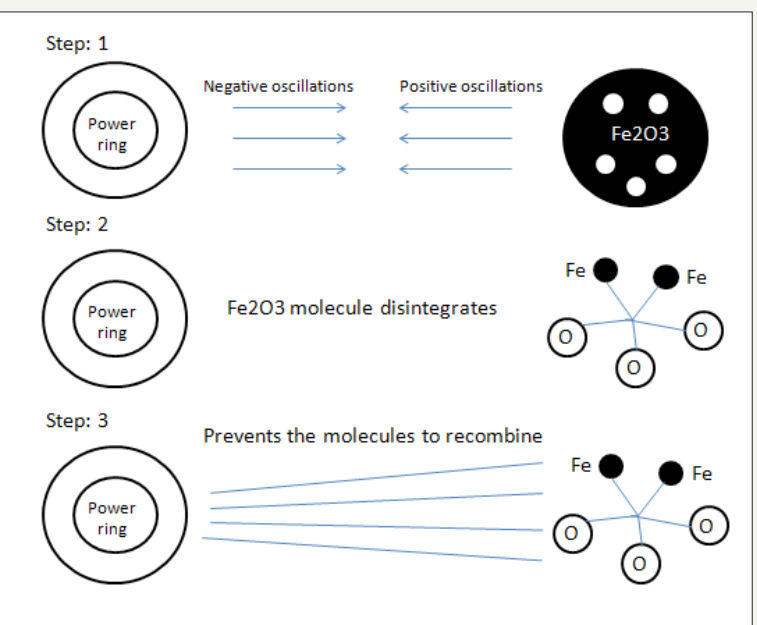

Figure 1: Functioning of a bio-signal ring.

\section{Harnessing of signals}

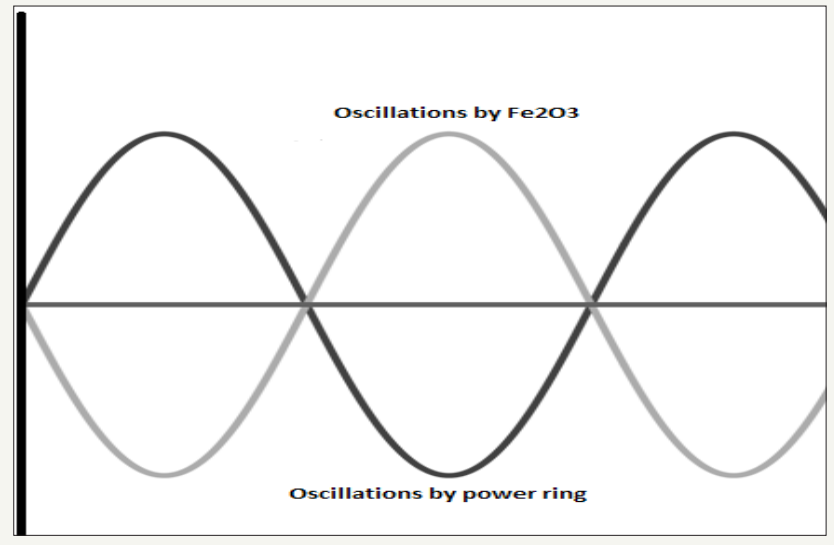

Figure 2: Interference of natural oscillations emitted by pollutants.

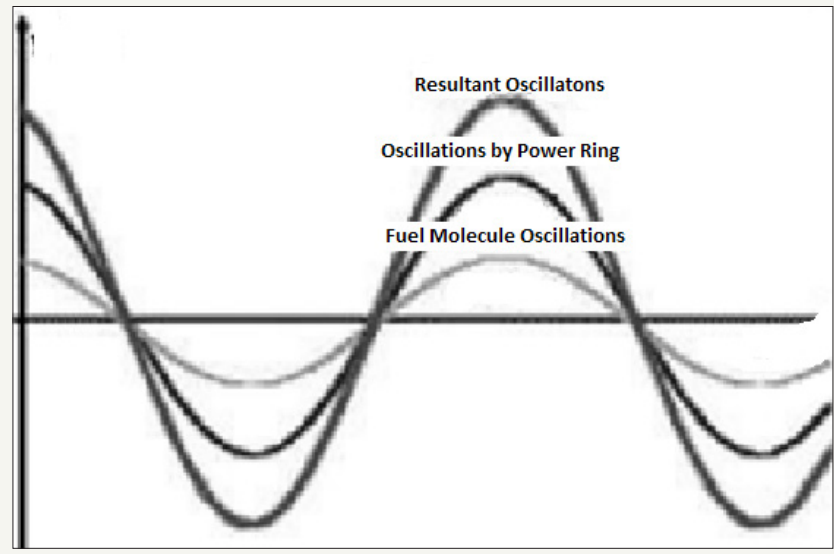

Figure 3: Overlaying of natural oscillations emitted by pollutants. 
The molecular fundamental oscillations of various substances has been isolated, mapped and stored in the Ring. This technology works using specifically modulated molecular oscillations not dependent upon magnetic forces or electrical pulses. Based on these oscillations of elements and molecules, a power ring has been developed. The aim is to influence the original oscillation of the element that has been targeted through new active oscillations in such a way that the physical properties of the element or of the molecules are modified. These manufactured oscillations are then programmed into the Power Ring and super imposed by a proprietary Laser Technology. This alloy can store an almost unlimited number of active oscillations and emit these to a liquid in a constant and stable format, independent of the ambient temperature. The active oscillations create a field within the ring, which penetrates all piping material and thus passes into the water or fluid. This Principle results in an 'Interference' or 'Overlaying' of natural oscillations emitted by pollutants in the liquid. Interference and Overlaying can best be described as cancelling sound using equal and opposite waves or playing two adjacent musical notes together to create another note (Figure 2,3).

\section{Vehicular Pollution}

The large majority of today's cars and trucks travel by using internal combustion engines that burn gasoline or other fossil fuels. The process of burning gasoline to power cars and trucks contributes to air pollution by releasing a variety of emissions into the atmosphere. Emissions that are released directly into the atmosphere from the tailpipes of cars and trucks are the primary source of vehicular pollution. But motor vehicles also pollute the air during the processes of manufacturing, refuelling, and from the emissions associated with oil refining and distribution of the fuel they burn [22-26].

The principal air-quality pollutant emissions from petrol, diesel, and alternative-fuel engines are carbon monoxide, oxides of nitrogen, un-burnt hydrocarbons and particulate matter. It is emissions of these pollutants that are regulated by the Euro emissions standards. Modern cars, if kept in good condition, produce only quite small quantities of the air quality pollutants, but the emissions from large numbers of cars add to a significant air quality problem. Carbon monoxide, oxides of nitrogen, and un-burnt hydrocarbons are gases, and are generally invisible. Particulate matter is usually invisible although under certain operating conditions diesel engines will produce visible particles, appearing as smoke. Petrol engines will also produce visible particles if they are burning engine oil or running "rich".

\section{Parameters of vehicular pollution}

Cars and trucks produce air pollution throughout their life, including pollution emitted during vehicle operation, refuelling, manufacturing, and disposal. Additional emissions are associated with the refining and distribution of vehicle fuel. Air pollution from cars and trucks is split into primary and secondary pollution. Primary pollution is emitted directly into the atmosphere; secondary pollution results from chemical reactions between pollutants in the atmosphere. Some of the major pollutants from motor vehicles are particulate matter, hydrocarbons, nitrogen oxides, carbon mono oxide and sulphur dioxide. Particulate matter (PM) is particles of soot and metals which give smog its murky colour. Fine particlesless than one-tenth the diameter of a human hair-pose the most serious threat to human health, as they can penetrate deep into lungs. PM is a direct (primary) pollution and a secondary pollution from hydrocarbons, nitrogen oxides, and sulphur dioxides [27-31].

Diesel exhaust is a major contributor to PM pollution. Hydrocarbons (HC) pollutants react with nitrogen oxides in the presence of sunlight to form ground level ozone, a primary ingredient in smog. Hydrocarbons contribute to ground-level ozone formation leading to risk of damage to the human respiratory system. Some kinds of hydrocarbons, in addition, are both carcinogenic and indirect greenhouse gases. Nitrogen oxides $\left(\mathrm{NO}_{\mathrm{x}}\right)$ pollutants cause lung irritation and weaken the body's defences against respiratory infections such as pneumonia and influenza. Oxides of nitrogen include nitrogen dioxide $\left(\mathrm{NO}_{2}\right)$ High levels of exposure have been linked with increased hospital admissions due to respiratory problems, while long-term exposure may affect lung function and increase the response to allergens in sensitive people Carbon monoxide (CO) when inhaled, blocks oxygen from the brain, heart, and other vital organs. Fetuses, new-born children, and people with chronic illnesses are especially susceptible to the effects of CO [32]. Carbon monoxide reduces the blood's oxygen-carrying capacity which can reduce the availability of oxygen to key organs. Sulphur dioxide $\left(\mathrm{SO}_{2}\right)$ Power plants and motor vehicles create this pollutant by burning sulphur-containing fuels, especially diesel. Sulphur dioxide can react in the atmosphere to form fine particles and poses the largest health risk to young children and asthmatics.

\section{Standards of vehicular pollution}

The standards are set by Central Pollution Control Board under the ministry of Environment and Forests and climate change. These are called Bharat Stage Emission Standards that regulate the output of the air pollutants from internal combustion engine equipment [33]. These standards based on European regulations were first introduced in 2000. The standard active now is Bharat Stage-IV norms which have been implemented since 2012. These norms help in bringing down pollution levels. Exposure to air pollution can lead to a number of cardiovascular and respiratory diseases.

\section{Measurement of vehicular pollution}

There are three approaches available to measure vehicle emissions. The first approach involves bringing vehicles into a laboratory, placing the vehicles on a dynamometer, and measuring their emissions as they are operated. The second approach is to place emission measurement and exhaust flow measurement equipment onto the vehicles and measure emissions from the vehicles as they are operated in the field. The third option is to use remote sensing to detect emissions from vehicles as they drive by. The traditional way to measure emissions from vehicles is to bring them into the laboratory and measure emissions as they are operated on a dynamometer [34]. 
In the better laboratories, the dynamometers can vary the load that they place on a vehicle on a second by second basis. Some older dynamometers are only capable of maintaining a steady load that can be changed, but only while the vehicle is not being tested. In either case, a load is placed on the vehicle that is equivalent to a load that the vehicle might experience while it is operating on a roadway and the emissions are measured from the vehicle. The actual emission measurements are typically made using a Constant Volume Sampling (CVS) system. This system works by pulling a constant volume of air that is larger than the amount of gases emitted by the vehicle being tested through a sampling duct. The exhaust gases from the vehicle being tested are mixed with this makeup air. The makeup air must, of course, be free of gases and particulate matter in order to not distort the testing process. Onroad vehicle emissions measurement equipment has only become realistically available since about 2003. The equipment is often referred to as portable emissions measurement equipment or PEMs.

\section{Pollution from Generator Sets}

Generator sets are the machines which uses diesel or gas as fuels for converting mechanical energy into electrical energy. Due to continuous development throughout the globe and increasing urbanization, electricity supply has become a basic necessity in day to day life. They are also seen as an alternative source of electricity in those developing regions where there is little or no power supply. This has increased the use of generator sets at an exponential level thereby creating an alarming level of pollution in all regions of the world. Emissions from a diesel generator set engine contain approximately $40 \%$ of toxic chemicals such as formaldehyde, arsenic and benzene which are carcinogenic in nature. Other contaminants such as nitrogen are emitted which are responsible for ozone layer depletion. Such compounds pose a threat to both humans as well as the environment. Generator sets in India may range from as low as $60 \mathrm{~kW}$ to $1 \mathrm{MW}$ and above. Generator sets have a large cumulative effect on the ecosystem.

\section{Parameters of generator set emissions}

A number of harmful products are emitted from generator set. The most significant harmful products are $\mathrm{HC}, \mathrm{NO}_{x^{\prime}} \mathrm{PM}$ and CO. Many reasons such as air-fuel ratio, combustion temperature, turbulence in the combustion chamber and air-fuel concentration make this out of question. $\mathrm{NO}_{\mathrm{x}}$ has the highest proportion of generator emission with a rate of more than 50\%. After NOx emission, the second highest emitted pollutant is PM. The following are the major pollutants from diesel generator set: Particulate matter (PM)Particulate matter emissions are resulted from combustion process. They may be generated from partly burned lube oil, ash content of fuel oil, agglomeration of very small particles of partly burned fuel. Most particulate matter is resulted from incomplete combustion of the hydrocarbons in the fuel and lube oil. It is reported that PM consists of elemental carbon (31\%), sulphates and moisture (14\%), un-burnt fuel (7\%), un-burnt lubricating oil (40\%) and remaining may be metals and other substances (Agarwal 2007).
These particles cause various health problems such as asthma, lung cancer, premature death and other cardiovascular issues [35].

Nitrogen oxides $\left(\mathrm{NO}_{\mathrm{x}}\right)$-major influences of the formation of NOx are the concentration of oxygen and temperature in the combustion. The amount of NOx produced is a function of maximum temperature in the cylinder, oxygen concentration, and residence time. Most of the $\mathrm{NO}_{\mathrm{x}}$ is formed at the starting of the combustion process. NOx emissions lead to formation of ozone, acidification, smog formation etc. $\mathrm{NO}_{2}$ has a level of toxicity five times greater than NO and also it causes direct human lung diseases. Hydrocarbons (HC)-Hydrocarbon emissions are due to unburned fuels as a result of insufficient temperature at the cylinder wall. Hydrocarbons consist of various species such as alkenes, alkenes and aromatics. Diesel engines generally emit low levels of hydrocarbons. In diesel engine the type of fuel, engine adjustment and design affect the hydrocarbon content (Table 1 \& 2).

Table 1: Emission norms for passenger cars.

\begin{tabular}{|c|c|c|}
\hline Norms & $\mathbf{C O}(\mathbf{g} / \mathbf{k m})$ & $\mathbf{H C}+\mathbf{N O}_{\mathbf{x}} \mathbf{( g / \mathbf { k m } )}$ \\
\hline 1991Norms & $14.3-27.1$ & $2.0($ Only HC) \\
\hline 1996 Norms & $8.68-12.40$ & $3.00-4.36$ \\
\hline 1998Norms & $4.34-6.20$ & $1.50-2.18$ \\
\hline India stage 2000 norms & 2.72 & 0.97 \\
\hline Bharat stage-II & 2.2 & 0.5 \\
\hline Bharat Stage-III & 2.3 & 0.35 (combined) \\
\hline Bharat Stage-IV & 1 & 0.18 (combined) \\
\hline
\end{tabular}

Table 2: Emission norms for two or three wheelers.

\begin{tabular}{|c|c|c|}
\hline Norms & $\mathbf{C O}(\mathbf{g} / \mathbf{k m})$ & $\mathbf{H C}+\mathbf{N O}_{\mathbf{x}} \mathbf{( g / \mathbf { k m } )}$ \\
\hline 1991 Norms & Dec-30 & $8-12$ (only HC) \\
\hline 1996 Norms & 4.5 & 3.6 \\
\hline India stage 2000 norms & 2 & 2 \\
\hline Bharat stage-II & 1.6 & 1.5 \\
\hline Bharat Stage-III & 1 & 1 \\
\hline
\end{tabular}

Hydrocarbons have various harmful effects on both human health and on environment. They play a significant role in the formation of ground level ozone. Hydrocarbons are toxic with the potential to respiratory track irritation and cause cancer. Carbon monoxide (CO)-Carbon monoxide results from incomplete combustion where oxidation process does not occur completely. Diesel engines are lean combustion engines having a consistently high air-fuel ratio. So, the formation of $\mathrm{CO}$ is minimal. Carbon monoxide is an odour less and color less gas. In humans, CO is inhaled by the lungs and transmitted into the bloodstream. Carbon monoxide reduces the blood's oxygen-carrying capacity which can reduce the availability of oxygen to key organs [36].

\section{Standards of generator set emissions}

Ministry of Environment and Forests, Government of India regulates the Emissions from new diesel engines used in generator 
set. The regulations impose type approval testing, production conformity testing and labelling requirements. The regulations

Table 3: Emission norms for heavy diesel vehicles. also include a list of authorized agencies for type approval testing Engine (Table 3-5).

\begin{tabular}{|c|c|c|c|c|}
\hline Norms & $\operatorname{CO}(\mathrm{g} / \mathrm{kmhr})$ & HC (g/kmhr) & $\mathrm{NO}_{\mathrm{x}}(\mathrm{g} / \mathrm{kmhr})$ & $\operatorname{PM}(\mathrm{g} / \mathrm{kwhr})$ \\
\hline 1991Norms & 14 & 3.5 & 18 & - \\
\hline 1996 Norms & 11.2 & 2.4 & 14.4 & - \\
\hline $\begin{array}{l}\text { India stage } \\
2000 \text { norms }\end{array}$ & 4.5 & 1.1 & 8 & 0.36 \\
\hline Bharat stage-II & 4 & 1.1 & 7 & 0.15 \\
\hline Bharat Stage-III & 2.1 & 1.6 & 5 & 0.1 \\
\hline Bharat Stage-IV & 1.5 & 0.96 & 3.5 & 0.02 \\
\hline
\end{tabular}

Table 4: Emission Standards for Diesel Engines $\leq 800 \mathrm{~kW}$ for Generator Sets (2004/2005).

\begin{tabular}{|c|c|c|c|c|c|c|}
\hline \multirow{2}{*}{ Power (P) } & \multirow{2}{*}{ Date } & $\mathrm{CO}$ & HC & $\mathrm{NO}_{\mathrm{x}}$ & PM & \multirow{2}{*}{$\begin{array}{c}\text { Smoke } \\
1 / \mathrm{m}\end{array}$} \\
\hline & & \multicolumn{4}{|c|}{ g/KWh } & \\
\hline \multirow{2}{*}{$P \leq 19 K w$} & 2004.01 & 5 & 1.3 & 9.2 & 0.6 & 0.7 \\
\hline & 2005.07 & 3.5 & 1.3 & 9.2 & 0.3 & 0.7 \\
\hline \multirow{2}{*}{$19 \mathrm{~kW}<\mathrm{P} \leq 50 \mathrm{~kW}$} & 2004.01 & 5 & 1.3 & 9.2 & 0.5 & 0.7 \\
\hline & 2004.07 & 3.5 & 1.3 & 9.2 & 0.3 & 0.7 \\
\hline $50 \mathrm{~kW}<\mathrm{P} \leq 176 \mathrm{~kW}$ & 2004.01 & 3.5 & 1.3 & 9.2 & 0.3 & 0.7 \\
\hline $176 \mathrm{~kW}<\mathrm{P} \leq 800 \mathrm{~kW}$ & 2004.11 & 3.5 & 1.3 & 9.2 & 0.3 & 0.7 \\
\hline
\end{tabular}

Table 5: Emission limits for Diesel Engines $>800 \mathrm{~kW}$ for Generator Sets.

\begin{tabular}{|c|c|c|c|c|}
\hline Date & $\begin{array}{c}\mathrm{CO} \\
\mathrm{mg} / \mathrm{Nm}^{3}\end{array}$ & 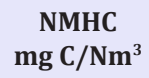 & $\begin{array}{c}\text { NOx } \\
\operatorname{ppm}(v)\end{array}$ & $\begin{array}{c}\mathrm{PM} \\
\mathrm{mg} / \mathrm{Nm}^{3}\end{array}$ \\
\hline Until 2003.06 & 150 & 150 & 1100 & $75 \mathrm{~b}$ \\
\hline $2003.07-2005.06$ & 150 & 100 & 970 (710a) & $75 c$ \\
\hline 2005.07 & 150 & 100 & 710 (360a) & $75 \mathrm{c}$ \\
\hline
\end{tabular}

a-For engines in plants of total power rating above $75 / 150 \mathrm{MW}$ located in urban/rural areas, respectively. b- $150 \mathrm{mg} / \mathrm{Nm}^{3}$ for engines fuelled with furnace oil.

c-100mg/ $\mathrm{Nm}^{3}$ for engines fuelled with furnace oil.

\section{Materials and Methods}

Opacity of smoke and smoke density factor has been measured to study the vehicular pollution from diesel engine and generator set with the help of smoke meter. Testing has been done as per IS: 8118: 2008. Smoke meter, Model no: 437C manufactured by AVL India Private Ltd was used and the analysis was done in the CASRAE lab, Delhi Technological University, Delhi. Opacity of smoke and smoke density factor has been measured to study the emission from generator set with the help of smoke meter. The analysis was done on generator set in electrical station No.1, Delhi Technological University, Delhi. CO, $\mathrm{NO}_{\mathrm{x}}, \mathrm{C}_{\mathrm{x}} \mathrm{H}_{\mathrm{y}}, \mathrm{SO}_{2}$ and Fuel efficiency has been measured from a Wagon $\mathrm{R}$ petrol Engine with the help of di-gas analyser Model no: 444 manufactured by AVL India Private Ltd. To test the increase in efficiency of the fuel by power ring, first the emissions of the engine without installing the power ring was tested. The engine was allowed to warm up for 30 minutes and then the emissions were tested by the respective instrument. The test was repeated by installing the power ring at the inlet of the fuel pipe [37].

\section{Result and Discussion}

\section{Emission test for petrol engine}

The exhaust from the Wagon $\mathrm{R}$ petrol engine, model: ED2 2009/10 having engine dynamometer was tested. The test was performed using Low Gas Analyzer in Biodiesel Laboratory. The various parameters recorded are listed in Table 6-13; Figure 4. There is a reduction in smoke emissions after installation of the Power Ring. The reduction in generator set engine thus calculated has been summed up in Table $14 \& 15$. This purpose of the study was to find the performance evaluation of bio-signal ring to reduce the level of pollution in diesel and petrol engines. According to the tests performed on the diesel and petrol engine, it can be observed that a significant decrease in the pollutants released by the engine can be achieved with the help of the ring. The overall reduction in diesel engines with the aid of the ring was found to be about $16.18 \%$, which shows that if these rings are fitted in diesel engine it can give a remarkable outcome in alleviating pollution levels. In case of petrol engine, considerable reduction in the value of various parameters was observed. The reduction percentage in hydrocarbons is about $25.3 \%$ and that in nitrogen oxides is $28.3 \%$. It is also noteworthy to see that besides reducing pollution levels, the fuel efficiency of the petrol engine has also increased from $90.40 \%$ to $95.30 \%$ as recorded from the instrument. It was also observed that time taken by the engine to consume $100 \mathrm{~mL}$ of fuel without the ring was 144 seconds, and on the application of the ring the time was reduced to 158 seconds. This goes on to show that the application of the ring is of importance not only in reducing pollutants from engine but also in increasing the efficiency of the engine. The reduction percentage is summed up in Figure 5 and later an average can be calculated for both the values. The purpose of the study was to find 
the performance evaluation of bio-signal ring to reduce the level of pollution in generator sets. According to the tests performed on the generator sets, it can be observed that $57.4 \%$ (on an average) decrease in the pollutants released by the engine can be achieved with the help of the ring [38].

Table 6: Parameters of petrol emission tested without ring.

\begin{tabular}{|c|c|c|c|c|c|c|}
\hline CO & NO & $\mathbf{C}_{\mathbf{x}} \mathbf{H}_{\mathbf{y}}$ & $\mathbf{S O}_{2}$ & $\mathbf{N O}_{\mathbf{x}}$ & $\begin{array}{c}\text { Fuel } \\
\text { Efficiency (\%) }\end{array}$ & Tc \\
\hline 277.1 & 42.3 & 1306 & 1.5 & 160.1 & 90.4 & $144 \mathrm{~s}$ \\
\hline
\end{tabular}

Table 7: Parameters of petrol emission tested with ring.

\begin{tabular}{|c|c|c|c|c|c|c|}
\hline CO & NO & $\mathbf{C}_{\mathbf{x}} \mathbf{H}_{\mathbf{y}}$ & SO $_{2}$ & NO $_{\mathbf{x}}$ & $\begin{array}{c}\text { Fuel } \\
\text { Efficiency (\%) }\end{array}$ & $\mathbf{T c}$ \\
\hline 265.1 & 87.5 & 975.4 & 0 & 114.9 & 95.3 & $158 \mathrm{~s}$ \\
\hline
\end{tabular}

Table 8: Parameters of petrol emission in vehicle without ring.

\begin{tabular}{|c|c|c|c|c|}
\hline RPM & CO & $\mathbf{C O}_{\mathbf{2}}$ & $\mathbf{O}_{2}$ & $\boldsymbol{\lambda}$ \\
\hline 2647 & 0.185 & 13.6 & 0.38 & 1.1548 \\
\hline
\end{tabular}

Table 9: Parameters of petrol emission in vehicle with ring.

\begin{tabular}{|c|c|c|c|c|}
\hline RPM & CO & $\mathbf{C O}_{2}$ & $\mathbf{O}_{2}$ & $\boldsymbol{\lambda}$ \\
\hline 2526 & 0.0003 & 17.31 & 0.07 & 1.002 \\
\hline
\end{tabular}

Table 10: Parameters of diesel engine emission tested without ring.

\begin{tabular}{|c|c|c|c|}
\hline $\begin{array}{c}\mathbf{N}(\%) \\
\text { Opacity }\end{array}$ & $\begin{array}{c}\mathbf{K}\left(\mathbf{m}^{-\mathbf{1}}\right) \\
\text { Smoke density } \\
\text { factor }\end{array}$ & $\begin{array}{c}\mathbf{T}\left({ }^{\circ} \mathbf{C}\right) \text { Heating } \\
\text { Chamber Temperature }\end{array}$ & $\begin{array}{c}\mathbf{n}\left(\mathbf{m i n}^{-\mathbf{1}}\right) \\
\mathbf{r p m}\end{array}$ \\
\hline 17.3 & 0.42 & 52 & 972 \\
\hline 16.9 & 0.41 & 55 & 972 \\
\hline
\end{tabular}

Table 11: Parameters of diesel engine emissions tested with ring.

\begin{tabular}{|c|c|c|c|}
\hline $\begin{array}{c}\text { N (\%) } \\
\text { Opacity }\end{array}$ & $\begin{array}{c}\mathbf{K}\left(\mathbf{m}^{-\mathbf{1}}\right) \\
\text { Smoke Density Factor }\end{array}$ & $\begin{array}{c}\mathbf{T}\left({ }^{\circ} \mathbf{C}\right) \text { Heating } \\
\text { Chamber Temperature }\end{array}$ & $\begin{array}{c}\mathbf{n}\left(\mathbf{m i n}^{-1}\right) \\
\mathbf{r p m} \\
\mathbf{0}\left({ }^{\circ} \mathbf{C}\right) \\
\text { Oil Temperature }\end{array}$ \\
\hline 14.4 & 0.36 & 55 & 24 \\
\hline
\end{tabular}

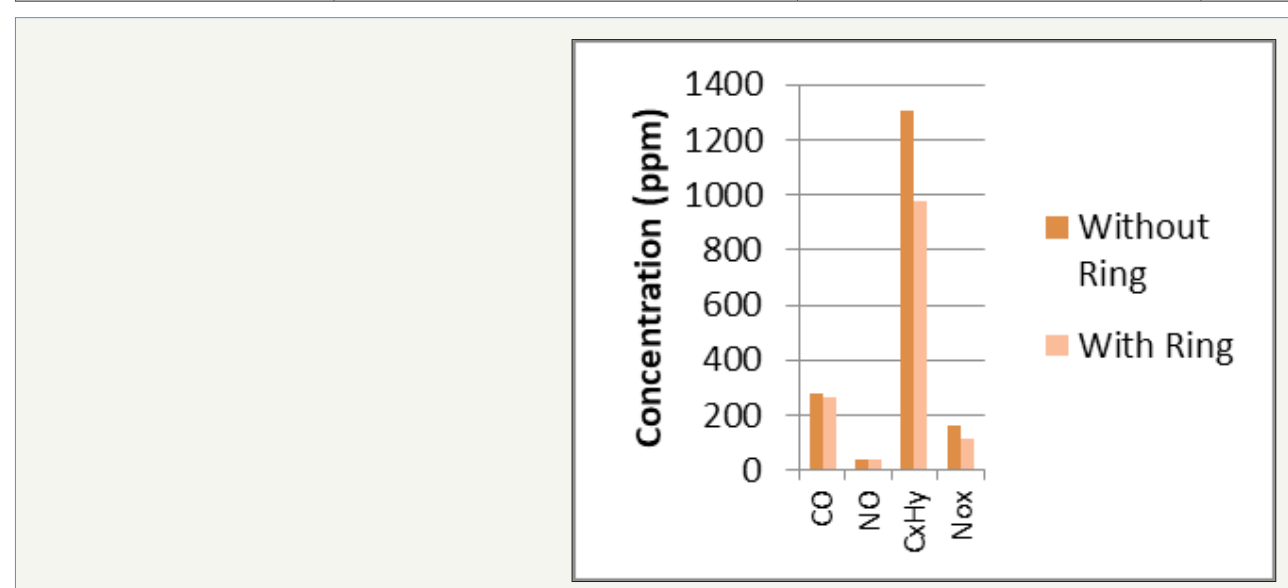

Figure 4: Parameters of Petrol engine emissions.

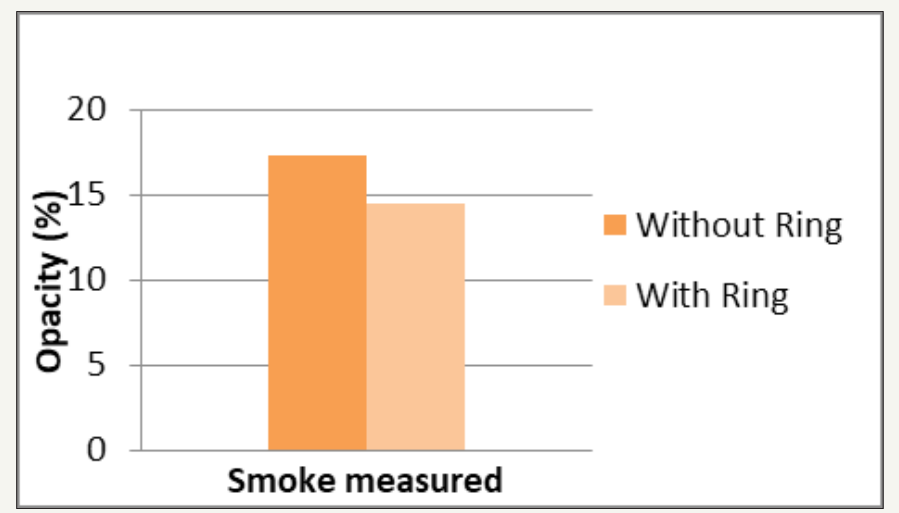

Figure 5: Comparison of diesel engine emissions. 
Table 12: Percentage reduction in emissions in diesel engine.

\begin{tabular}{|c|c|c|c|}
\hline Parameters & Without Ring & With Ring & Reduction (\%) \\
\hline $\mathrm{CO}$ & 277.1 & 265.1 & 4.3 \\
\hline $\mathrm{NO}$ & 42.3 & 87.5 & 11.3 \\
\hline $\mathrm{C}_{\mathrm{x}} \mathrm{H}_{\mathrm{y}}$ & 1306 & 975.4 & 25.3 \\
\hline $\mathrm{SO}_{2}$ & 1.5 & 0 & 100 \\
\hline $\mathrm{No}_{\mathrm{x}}$ & 160.1 & 114.9 & 28.3 \\
\hline
\end{tabular}

Table 13: Percentage reduction in emissions in diesel engine.

\begin{tabular}{|c|c|c|c|}
\hline \multirow{2}{*}{ Parameter } & Without Ring & With Ring & Reduction (\%) \\
\hline \multirow{2}{*}{ Opacity } & 17.3 & 14.4 & 16.76 \\
\cline { 2 - 4 } & 16.9 & 14.6 & 13.6 \\
\hline
\end{tabular}

Table 14: Parameters of generator set emission without ring.

\begin{tabular}{|c|c|c|c|c|c|}
\hline $\begin{array}{c}\text { Duration } \\
\text { After } \\
\text { Warming } \\
\text { (minutes) }\end{array}$ & $\begin{array}{c}\text { Opacity } \\
\text { (N) }\end{array}$ & (K) & $\begin{array}{c}\text { Oil } \\
\text { Temperature } \\
\text { (T) }\end{array}$ & $\begin{array}{c}\text { RPM } \\
\text { (n) }\end{array}$ & $\begin{array}{c}\text { Engine } \\
\text { Tempera- } \\
\text { ture (t) }\end{array}$ \\
\hline 30 & 77 & 1.27 & 91 & 742 & 22 \\
\hline 45 & 88.6 & 1.25 & 91 & 742 & 23 \\
\hline
\end{tabular}

Table 15: Parameters of generator set emission with ring.

\begin{tabular}{|c|c|c|c|c|c|}
\hline $\begin{array}{c}\text { Duration } \\
\text { After Warming } \\
\text { (minutes) }\end{array}$ & Opacity & $\mathbf{( K )}$ & $\begin{array}{c}\text { Oil Tem- } \\
\text { perature }\end{array}$ & RPM & $\begin{array}{c}\text { Engine tem- } \\
\text { perature }\end{array}$ \\
\hline & $(\mathrm{N})$ & & $(\mathrm{T})$ & $(\mathrm{n})$ & $(\mathrm{t})$ \\
\hline 30 & 77 & 1.27 & 91 & 742 & 22 \\
\hline 45 & 88.6 & 1.25 & 91 & 742 & 23 \\
\hline
\end{tabular}

\section{Conclusion}

From the study it is concluded that the Power Ring is very efficient in reducing the pollutants from the atmosphere. Various parameters constituting the smoke in have significantly decreased in the engine exhaust after installation of the ring. The ring works effectively on diesel as well as petrol engines. In petrol engines, maximum reduction is in the oxides of nitrogen. The ring was found to be very efficient in reducing the pollution level from the generator exhaust and can reduce a significant amount of pollution from the country if used effectively in all areas. According to the tests performed on the generator set, it can be observed that there is a considerable reduction in the value of smoke emissions. The reduction in percentage of opacity was $54.7 \%$ as recorded by the smoke meter.

Besides reducing the pollution, it proves to be economical to install the ring into to engine inlets of the motor vehicles and generator sets. It is so because an increase in burning capacity of the fuel is observed. This indicates increase in fuel efficiency which makes the fuel last longer. Also, as per our previous study, there is a significant increase in efficiency of the fuel after installation of the ring in addition to reduction in pollutants in vehicle engine. This goes on to show that the application of the ring is of importance in two ways, firstly, reducing pollutants from engine and secondly, increasing the efficiency of engines Figure 6-8.

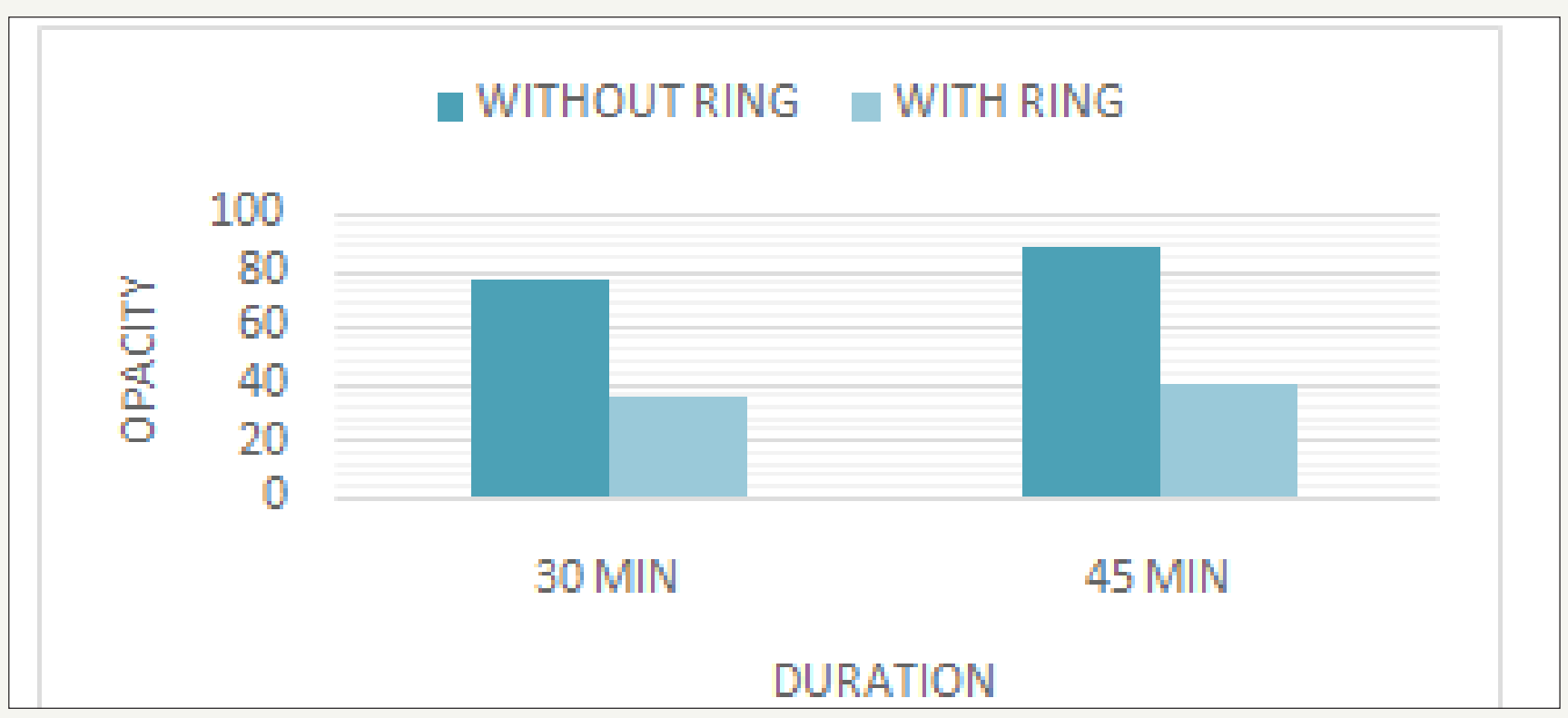

Figure 6: Generator set emission comparison. 


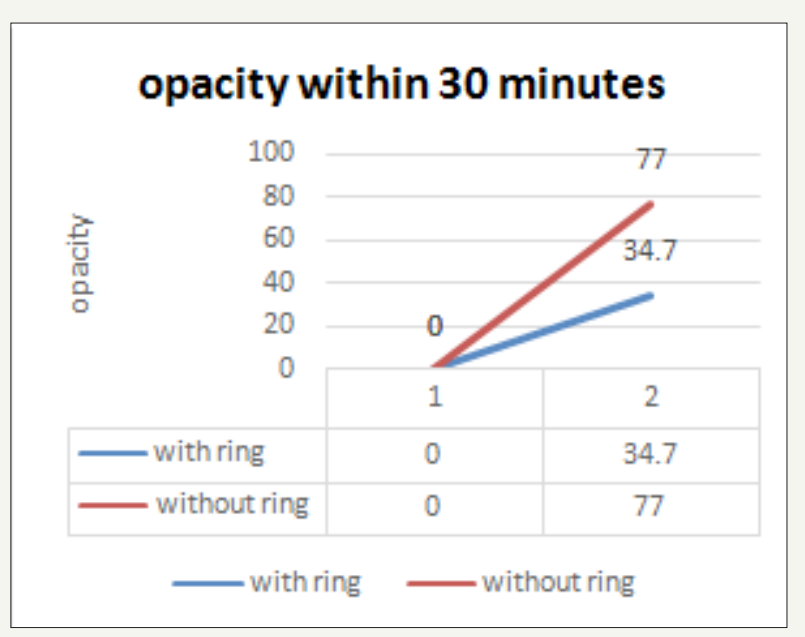

Figure 7:

Figure 8:

The Power Ring is the much needed means to get the rising levels of pollution in control and further also proves to be economical. We recommend the incorporation of Power ring in private and govt. vehicles and generator set to be made compulsory. The idea of the Power Ring is to atomize the fuel at the very inlet of the engine. This gives two positive results, firstly, burning the fuel much more efficiently and secondly, minimizing the emission of the un-burnt carbon particles. This not only helps in reducing the pollution at the exhaust valve, but also increases the efficiency of the fuel by about 5-30\%, making it last longer. The Power Ring can be installed in petrol engines, diesel engines and generators. The installation process being simple, it can be attached on the fuel pipe by any individual. Since, automobiles contribute to $80-90 \%$ of the air pollution; there is tremendous scope of this Power Ring in the present as well as in the future as it is high time for mankind to act on the rising levels of air pollution especially in megacities.

\section{References}

1. Singh SK, Surbhi J, Tejasvini A, Yukti S, Nidhi P (2017) Performance evaluation of Biosignal ring for reduction of pollution level in diesel and petrol engines. IJIRSET 6(7).
2. (2002) New non-invasive sensor can detect brainwaves remotely. University of Sussex, UK.

3. Sullivan TJ, Deiss SR, Cauwenberghs G (2007) A low-noise, non-contact EEG/ECG sensor. Biomedical Circuits and Systems Conference, pp. 154157.

4. Yu MC, Patrick NG, Eric K, Joseph K, Jennifer F, et al. (2010) Wireless noncontact cardiac and neural monitoring. Proceedings of Wireless Health 2010 (WH'10), pp. 15-23.

5. Harland CJ, Clark TD, Prance RJ (2002) Electric potential probes-new directions in the remote sensing of the human body". Measurement Science and Technology 13(2): 163-169.

6. Harland CJ, Clark TD, Peters NS, Everitt MJ, Stiffell PB (2005) A compact electric potential sensor array for the acquisition and reconstruction of the 7-lead electrocardiogram without electrical charge contact with the skin. Physiological Measurement 26(6)

7. Oehler M, Ling V, Melhorn K, Schilling M (2007) A multichannel portable ECG system with capacitive sensors. Physiological Measurement 29(7): 783-793.

8. Brouse A (2012) A young person's guide to brainwave music: Forty years of audio from the human EEG. eContact! 14.2-Biotechnological Performance Practice/Pratiques de Performance Biotechnologique. CEC, Montréal, Canada. 
9. Ortiz M. A brief history of biosignal-driven art: From biofeedback to biophysical performance. eContact! 14.2-Biotechnological Performance Practice/Pratiques de performance biotechnologique. CEC, Montréal, Canada.

10. Lopes P, chippewa J (2012) Performing biological bodies: An open conversation with marco donnarumma, Claudia Robles and Peter Kirn at body controlled \#4-Bio Interfacing. eContact! 14.2-Biotechnological Performance Practice/Pratiques de performance biotechnologique. CEC, Montréal, Canada.

11. (2012) eContact! 14.2-Biotechnological Performance Practice/Pratiques de performance biotechnologique. CEC, Montréal, Canada.

12. For EG, Gümşel EB, Ozgon O (2013) Prediction of ABC removal by different materials from landfill leachate: Modeling of experimental results XYZ technique. The Scientific World Journal 52(2).

13. Rosen, Erwin M (1975) The peterson automotive troubleshooting \& repair manual. Grosset \& Dunlap Inc, USA, ISBN: 978-0-448-11946-5.

14. Infrared remote sensing of on-road motor vehicle emissions in Washington State. USA.

15. Kebin HE, Zhangqiang, Hong HOU (2010) Point source of pollution: Local effects and its control types and amount of vehicular pollution 1. P. 442.

16. Jones M (2002) Advanced opacity meters: their potential role in future emission testing legislation for diesel vehicles. Proc of the $6^{\text {th }}$ ETH Conference on Nanoparticle Measurement, Zurich, Switzerland.

17. Website of central pollution control board. Ministry of environment and forests.

18. James L, Micheal W, Kebin H, Nicolus D, Sebestian T, et al. Air quality management.

19. Central pollution control board 2008 vehicular emissions.

20. Nicolus D, Jim L, Mike W.

21. Akane S, Takashi T, Haruo O (2009) Application using earphone with biosignal sensors.

22. Hasan MA (2009) Detection and processing techniques of FECG Signal for fatal monitoring. Biological procedures online, p. 33.

23. Yang J (2009) A new filtering algorithm for removing salt and pepper noise. International conference on environmental science and information application technology, pp. 1355-1358.
24. Website of biomedical engineering, Application of biosignal.

25. Michel B, Jeremy R, Cooper S. Biosignal analysis and its applications. Centre for Intelligent Machines, McGill University St Montreal, Canada.

26. Anders S, Lotze M, Grodd W, Birbaumer N (2004) Brain activity underlying emotional valence and arousal: A response-related Fmri study. Human brain mapping 23(4): 200-209.

27. Dhar PL, Singh SK (2001) Studies on solid desiccant based hybrid airconditioning systems. Applied Thermal Engineering 21(2): 119-134.

28. Singh SK, Rao DN, Agrawal M, Pandey J, Naryan D (1991) Air pollution tolerance index of plants. Journal of Environmental Management 32(1): 45-55.

29. Singh SK, Rao DN (1983) Evaluation of plants for their tolerance to air pollution. Proceedings of symposium on air pollution control.

30. Agrawal M, Singh SK, Singh J, Rao DN (1991) Biomonitoring of air pollution around urban and industrial sites. Journal of Environmental Biology.

31. Allaa MA, Singh SK, Jabir AL (2015) Air quality assessment: A statistical approach to stationary air monitoring stations. International Journal of Advanced Research 3(3): 68-80.

32. Gour AA, Singh SK, Tyagi SK, Mandal A (2015) Variation in Parameters of Ambient Air Quality in National Capital Territory (NCT) of Delhi (India). Atmospheric and Climate Sciences 5:13-22.

33. Aenab AM, Singh SK, Lafta AJ (2013) Critical assessment of air pollution by ANOVA test and human health effects, Atmospheric Environment 71: 84-91.

34. Seaton A, Godden D, MacNee W, Donaldson K (1995) Particulate air pollution and acute health effects. 345(8943):176-178

35. Goldsmith JR, Friberg LT (1977) Effects of air pollution on human heaalth Air pollution. Academic Press New York, USA.

36. Fleur ST, Nicholas (2015) Atmospheric greenhouse gas levels hit record, Report says. New York Times, USA.

37. Saber EM, Heydari G (2012) Flow patterns and deposition fraction of particles in the range of $0.1-10 \mu \mathrm{m}$ at trachea and the first third generations under different breathing conditions. Computers in Biology and Medicine 42(5): 631-638.

38. (2002) Remote heartbeat monitor will outperform current technology. University of Sussex Bulletin, UK.

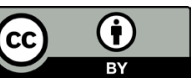

Creative Commons Attribution 4.0 International License

For possible submissions Click Here
Submit Article

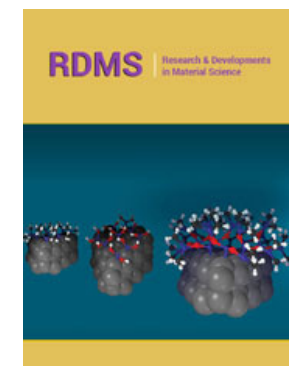

\section{Research \& Development in Material Science}

\section{Benefits of Publishing with us}

- High-level peer review and editorial services

- Freely accessible online immediately upon publication

- Authors retain the copyright to their work

- Licensing it under a Creative Commons license

- Visibility through different online platforms 